National Aeronautics and

Space Administration

Washington, D.C. 20546

AC 202 755-8370

Nicholas Panagakos.

Headquarters, Washington, D.C.

For Release:

(Phone: 202/755-3680)

IMMEDIATE

Victor Seigel

Headquarters, Washington, D.C.

(Phone: 202/755-3352)

RELEASE NO: $79-35$

\title{
PLANETARY EXPLORATION BY NASA SPACECRAFT
}

The attached summarizes chronologically by launch date NASA's planetary exploration program. It lists the planet, the spacecraft, launch and encounter dates and briefly summarizes scientific findings. This summary is provided

for information and reference.

(NASA-Neus-Release-79-35); PLANETARY

N79-19011

EXPLORATION BY NASA SPACECRAFT (National

Aeronautics and space Administration) 5

$\operatorname{CsCL} 22 \mathrm{~A}$

Jnclas

$00 / 1218711$. 
Mariner 4

\section{Nov. 28,1964}

Venus

Mar8

Mars

$\operatorname{Mar} 8$

Jupiter

Pioneer 10

March 3, 1972

Pioneer 11
April 6, 1973

(March 1979)

Encounter

Flyby:

DeC: 14,1962

Flyby:

July 14, 1965

Flyby:

Oct. 19, 1967

Flyby:

July 31, 1969

Flyby

Aug. 5, 1969

Orbited and studied Mars from Nov. 13. 1971 to oct. 27. 1972.

Flyby:

Dec. 4, 1973

Flyby:

Dec. 5, 1974

\section{Major Findings or Goals}

Heavy atmosphere, 100 times the pressure of Earth's, mostly carbon dioxide; scorching (more than 800 degrees F) surface, no magnetic field.

Cratered Moon-like surface revealed in 21 close-up pictures from distance of about $9,656 \mathrm{kilometers}(6,000 \mathrm{miles})$. No evidence of artificial canals or of flowing water. Atmospheric pressure about a hundredth that of Earth, mostly carbon dioxide.

Confirmed and refined Mariner 2 findings. Found exosphere of venus is made up of hydrogen as is that of Earth. Detected Venusian ionosphere.

Mariners 6 and 7 took about 200 close-up pictures of Mars that showed smooth, cratered and chaotic surfaces. Confirmed and refined atmospheric data. Came as close as 3,219 km (2,000 mi.) to Mars.

More than 7,000 closeup photographs revealed exciting new Martian features: volcanic mountains including one taller and broader than any on Earth; a canyon long enough to stretch from San Francisco to New York City; signs that rivers and possibly seas could have existed on Mars in times past; and dust storms that enveloped the whole planet.

Pioneer 10. provided world's first close-up pictures of Jupiter. Analyses of photographs and data from Pioneers 10 and 11 indicated that below its deep atmosphere, Jupiter may be composed mostly of liquid hydrogen with no solid surface; that the Great Red spot may be a hurricane-like storm; that the colorful cloud bands are rising and falling air masses; that the Jovian magnetic field is much larger and more complex and its trapped radiation far more intense than previously assumed; and that Jupiter may be the only solar system body other than the sun to emit particle radiation. New knowledge also was gained about the satellites Io, Europa, Ganymede and Callisto. 


\section{Planet}

\section{Spacecraft}

Pioneer 11

Saturn

Venus

Mariner 10

Nov. 3, 1973

Mercury

Mariner 10

Nov. 3, 1973

Viking I

Aug. 20, 1975

viking 2

\section{Launch Date}

April 6, 1973
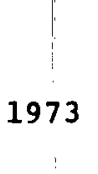

Mars

Mars

\section{Encounter}

Flyby:

Sept. 1, 1979

Flyby:

Feb. 5, 1974

Flybys:

March 29, 1974

Sept. 21, 1974

March 16, 1975

July 20, 1976

Lander 1

Touchdown

Sept. 3, 1976

Lander 2

Touchdown

\section{Major Findings or Goals}

To take close-up color pictures of Saturn and 1 ts rings and gather data on the atmosphere, magnetic fleld and other features.

Picture-taking spacecraft failed to find holes in clouds shrouding Venus. In ultraviolet, however, pictures revealed topmost clouds circle planet 60 times faster than planet rotates. Other instruments indicated the ionosphere results from interaction of Venus' atmosphere and solar wind and confirmed that the atmosphere is 95 per cent carbon dioxide. surface air pressure is about 100 times Earth's and surface temperature is about 450 degrees C (900 degrees F), hot enough to melt lead or zinc.

First close-ups of Mercury reveal an ancient surface st111 bearing the scars of meteorite impacts that occurred billions of years ago and huge scarps (cliffs), apparently caused by crustal compression as the planet's interior cooled. A Mercurian magnetic field about a hundredth the magnitude of Earth's was detected as was a thin atmosphere of argon, neon and helium, with a trillionth the density of Earth's. Temperatures were measured from 510 degrees $C$ (950 degrees $F$ ) on the sunlit side to -210 degrees $C$ ( 350 degrees $F$ ) on the dark side.

Studied Mars from orbit and from two different locations on the surface. Pictures of Martian surface from Landers show it as resembling deserts on Earth. However, analyses of surface show it to be drier than Earth's driest deserts. Martian atmosphere, about a hundredth the density of Earth's, otherwide has all of the elements needed to support life: nitrogen, carbon, oxygen and water vapor. Considerable quantities of water locked in polar ice caps were detected from orbiters. No organic molecules detected in soil by Lander. Lander analyses of soil samples gave puzzling results that neither proved nor disproved existence of microbial life on Mars. 


\begin{tabular}{|c|c|c|c|c|}
\hline Planet & Spacecraft & Launch Date & Encounter & Major Findings or Goals \\
\hline Jupiter & Voyager 2 & Aug. 20, 1977 & $\begin{array}{l}\text { Flyby: } \\
\text { July } 1979\end{array}$ & $\begin{array}{l}\text { To conduct close-up studies of Jupiter, its ring discovered } \\
\text { by Voyager I and its major moons: Io, Europa, Callisto, } \\
\text { Ganymede and Amalthea. }\end{array}$ \\
\hline Jupiter & Voyager 1 & Sept. $5,1977^{*}$ & $\begin{array}{l}\text { Flyby: } \\
\text { March } 3-6, \\
1979\end{array}$ & $\begin{array}{l}\text { Provided the first detailed views of the surfaces of Io, } \\
\text { Ganymede and Callisto. Io was discovered to have active vol- } \\
\text { canoes and greater volcanic activity than Earth. Ganymede } \\
\text { and Callisto showed the scars of ancient meteorite bombard- } \\
\text { ment; other surface relief shown is attributed to their } \\
\text { assumed mantles of liquid water. A particles ring only } 29- \\
32 \mathrm{~km}(18-20 \mathrm{mi}) \text { thick was discovered around Jupiter. Amal- } \\
\text { thea, the tiny innermost satellite, was found to be elon- } \\
\text { gated in shape and reddish. Voyager pictures revealed sur- } \\
\text { face details as small as about .37 } \mathrm{km}(.23 \mathrm{mi} .) \text { across on Io, } \\
2.1 \mathrm{~km}(1.3 \mathrm{mi}) \text { on Ganymede and } 2.2 \mathrm{~km}(1.4 \mathrm{mi}) \text { on Cal- } \\
\text { listo and cloud features as small as } 5.1 \mathrm{~km}(3.2 \mathrm{mi}) \text { on } \\
\text { Jupiter. }\end{array}$ \\
\hline Saturn & Voyagers 1 and & 2 & $\begin{array}{l}\text { Flybys: } \\
\text { Voyager } 1, \\
\text { Nov. } 1980 \text {; } \\
\text { Voyager } 2 \text {, } \\
\text { Aug. } 1981 .\end{array}$ & $\begin{array}{l}\text { To conduct close-up studies of Saturn, its rings and its } \\
\text { moons, particularly Titan, which has an atmosphere. }\end{array}$ \\
\hline Uranus* * & voyager 2 & & $\begin{array}{l}\text { Flyby: } \\
\text { Jan. } 1986\end{array}$ & $\begin{array}{l}\text { To conduct close-up studies of Uranus, its rings and its } \\
\text { moons. }\end{array}$ \\
\hline
\end{tabular}

* Although launched later, Voyager 1 had a trajectory that took it to Jupiter faster than Voyager 2.

** Optional. 


\section{Planet}

Venus

Venus

\section{Spacecraft}

Pioneer Venus 1

Pioneer

Venus 2
May 20,1978

Aug. 8, 1978

\section{Encounter}

placed into orbit Dec. 4, 1978 .

Dec. 9, 1978. Separated into five probes that measured the Venus atmosphere as they descended to the surface. Although not designed to survive after landing, one probe transmitted information for 67 minutes after impact.

\section{Major Findings or Goals}

Discovered that an isotope of the rare gas argon exists in a much greater abundance on Venus than on Earth. The discovery contradicts theories on planetary formation that the closer a planet is to the Sun the more it should be depleted of its original gases. Provided new support for theory that intense heat on venus is due to runaway greenhouse effect. Venus' overall atmosphere was shown to be about 97 per cent carbon dioxide, 1-3 per cent nitrogen and $0.1-0.4$ per cent water vapor with traces of other gases. Clouds are composed mainly of oxygen, water vapor and sulphur dioxide. The sky of Venus is clear of particles below the clouds, which are separated into three distinct layers. Radar mapping from orbit indicates the Venus topography resembles Earth's.

列

